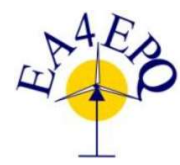

International Conference on Renewable Energies and Power Quality (ICREPQ'18)

Salamanca (Spain), $21^{\text {th }}$ to $23^{\text {th }}$ March, 2018

Renewable Energy and Paver Quality. Fournal (RE\&PQJ)

ISSN 2172-038 X, No.16 April 2018

\title{
Minimising the levelised cost of energy and grid impact by multi- objective optimisation of wind turbine sizing
}

\author{
J. Serrano González ${ }^{1}$, M. Burgos Payán ${ }^{1}$, J. Riquelme Santos ${ }^{1}$ and J. Almeida ${ }^{2}$ \\ ${ }^{1}$ Department of Electrical Engineering \\ University of Seville, 41092, Seville, Spain \\ ${ }^{2}$ Faculty of Sciences of Lisbon University, 1749-016 Lisbon, Portugal \\ Phone/Fax number: +34 954487285, e-mail: javierserrano@us.es
}

\begin{abstract}
This paper introduces a novel methodology to optimise the sizing of wind turbines in order to simultaneously minimising the levelised cost of energy ( $\mathrm{LCoE}$ ) and maximizing the capacity factor (resulting in less intermittence and grid impact). The proposed tool aims at selecting the optimal combination of the three main design variables (rated power, rotor diameter and hub height) which define the sizing of modern three-bladed wind turbines. The classical design of wind turbines aims at minimizing the LCoE. However, as wind technology has evolved toward bigger wind turbines, and especially toward larger rotors, new site-specific solutions have appeared in the market by finding the optimal combination between rated power, rotor diameter and hub height. This natural optimisation carried out by the wind industry has enabled the deployment of new projects at low-wind locations to be economically viable. However, a similar approach can be addressed not only to minimise the cost of energy but also the impact of wind intermittency on the electrical grid.
\end{abstract}

\section{Key words}

Multi-objective optimization, capacity factor, levelised cost of energy, wind energy, wind turbine.

\section{Introduction}

Wind industry is pushing forward to reduce costs and achieve 'grid parity'. In recent years there have been some signs which suggest that cost of wind energy is increasingly closer to the generating cost of other conventional sources. Additionally, it is clear that the efforts of the industry of reducing costs are paying off and wind energy is becoming more competitive in low wind locations were higher LCoE is required (lower production and higher cost per unitary power installed).

On the other hand, recently, a new trend towards a modular approach is being implemented by manufacturers in order to offer more flexible products while keeping a standardised component production. Two main strategies are currently used by manufacturers: (i) employing the same platform (same/similar power rating) combined with different rotor diameters and hub heights or (ii) using the same rotor for several machine ratings. This clear trend in the wind industry towards more customised products can even go beyond a few options about rotor diameters and tower heights, since the industry is making effort in researching on more tailor-made products —as it is the case of the Hyller project [1] which aims at developing blades with customized blade length - or the possibility of achieving tailored heights by concrete or hybrid towers recently introduced in the market.

In this context, it can be expected that wind turbine manufacturers will introduce new technological solutions aimed not only at reducing costs, but also increasingly at improving network integration.

There are several works in the literature aiming at selecting the most suitable wind turbine model considering other non-economic aspects. Jangamshetti and Guruprasada [2] proposed a method to achieve a compromise solution between capacity factor and rated power of wind turbines, based on maximising the socalled wind turbine performance index (TPI), defined as the product of the normalised rated power by the capacity factor divided by the product of the maximum values (achieved by the wind turbine model under study) of both normalised rated power and capacity factor. The TPI has also been used by other authors to analyse the selection of wind turbines under certain wind conditions [3], [4], [5]. This criterion can be used to achieve a compromise solution between generated energy and capacity factor. However, it does not guarantee that such compromise solution is near to the efficient frontier when intending to simultaneously optimise both generated energy and capacity factor. Albadi and Saadany [6] presented a novel wind turbine selection matching procedure based on the so-called Turbine-Site Matching Index (TSMI) index which refers to the ratio between capacity factor and cost, depending both variable on height of the tower. This approach, although interesting, since it models both capacity factor and costs, does not consider the volume of generated energy which eventually is an essential aspect 
for the profitability of the project. Hu and Cheng [7] presented in 2006 an iterative methodology for optimal selection of wind turbine depending on the characteristics of the wind behaviour at the target location. The approach proposed by the authors took into account six variables: two corresponding to the wind behaviour model through the Weibull distribution (i.e., shape and scale parameters) and four variables inherent to the characteristics of the wind turbine model (cut-in speed, cut-out speed, rated power and the rated wind speed). The objective of the presented approach was maximising the capacity factor by considering a predefined set of wind turbine models. However, the model proposed by the authors did not take into account the cost of the wind turbines neither the total produced energy which are very important aspects when selecting the wind turbine model.

This paper introduces a theoretical framework for optimising the design of wind turbines with a twofold objective: (i) to minimise the cost of energy (which is the primary objective currently pursued by the wind power industry) and (ii) to maximise the capacity factor (which would allow wind farms to behave more similarly to conventional generation plants reducing, to a certain extent, the intermittency of generation). However, these two objectives are opposing terms, since, for certain wind conditions, increasing the capacity factor is achieved either by (i) increasing the swept area by the rotor or by installing taller towers (which, under certain conditions, can significantly increase upfront costs in exchange for moderate increases in the energy produced) or (ii) by using electric generators of lower nominal capacity (which would negatively affect the annual energy produced at the expense of slightly reducing investment costs). Therefore, the multi-target optimization methodology proposed in this work will enable to obtain different solutions along the optimal Pareto front. In such a way that it is possible to select a trade-off solution, as well as to economically assess the additional cost of increasing the capacity factor compared to the solution of the classic approach aimed at minimising exclusively the LCoE.

After this introduction, the rest of the paper is organized as follows: Section 2 describes the wind turbine energy production model. The optimization framework and proposed methodology are presented in Section 3. Section 4 discusses the results of proposed test case and, finally, conclusions and final remarks are included in Section 5.

\section{Wind energy production model}

The statistical behaviour of the wind at a given altitude is approximated by the Weibull distribution function, that describes frequency, $p(v)$, for a given wind speed, $v$, as a function of the shape parameter, $K$, and the scale parameter, $C$, using the formula:

$$
p(v)=\frac{K}{C}\left(\frac{v}{C}\right)^{K-1} \exp \left(-\left(\frac{v}{C}\right)^{K}\right)
$$

Wind speed depends on altitude due to the existing friction of the air with the ground surface, this phenomenon is known as wind shear effect. Once the wind speed, $v\left(z_{r e f}\right)$, measured at a given reference height, $z_{r e f}$, is known, the corresponding wind speed at a different height, $z$, can be calculated using an exponential function, where $z_{0}$ is the length of roughness for the terrain:

$$
v(z)=v\left(z_{r e f}\right) \frac{\ln \left(z / z_{0}\right)}{\ln \left(z_{r e f} / z_{0}\right)}
$$

On the orher hand, the power curve of the wind turbine can be defined as follows:

$$
\begin{aligned}
& P_{W T}(v)=\frac{1}{2} \rho \cdot C_{P} \cdot \pi \cdot R^{2} \cdot v^{3} \quad \forall v_{c i} \leq v \leq v_{n} \\
& P_{W T}(v)=P_{n} \quad \forall v_{n}<v \leq v_{c o}
\end{aligned}
$$

where $P_{W T}(v)$ is the output power for the wind speed $v, \rho$ is the air density, $R$ is the rotor radius of the wind turbine, $C_{P}$ is the maximum power coefficient of the wind turbine, $\mathrm{v}_{c i}$ and $\mathrm{v}_{c o}$ are, respectively, the cut-in speed and cut-out speed of the wind turbine, $v_{n}$ is the rated wind speed. In this paper, in order to consider a standard power curve for all the range of wind turbine rated power, the rated wind speed is calculated as the wind speed at which the wind turbine achieves the rated power.

The annual energy produced (AEP) is calculated by taking into account the power curve of the wind turbine, $P_{W T}(v)$, and the wind speed probability — obtained by the Weibull distribution:

$$
A E P=T \cdot k_{\text {losses }} \sum_{i=1}^{N_{s}} \sum_{j=1}^{N_{W T}} p_{S i} \int_{v_{c i}}^{v_{c o}} P_{W T}\left(v_{i j}^{\prime}\right) p\left(v_{i j}^{\prime}\right) d v^{\prime}
$$

where $T$ is the number of hours per year $(T=8760 \mathrm{~h})$, $k_{\text {losses }}$ is a losses multiplication factor - which takes into account losses related to several aspects such as electrical losses, wake effect, rotor misalignment, among others.

\section{Optimization framework}

A multi-objective genetic algorithm has been implemented to tackle the proposed optimization problem. Each potential solution, $x$, is defined by an array of three variables: $x=\left[P_{n}, S P, R_{H D}\right]$; where $P_{n}$ is the rated power of the wind turbine, $S P$ is the Specific Power (which is defined as the ratio between rated power of the wind turbine and the area swept by the rotor blades) and $R_{H D}$ is the ratio between hub height and rotor diameter. Under this proposed multi-objective optimization approach, two objectives are simultaneously considered: (i) minimization of the levelised cost of energy and (ii) maximization of the plant capacity factor.

The levelized cost of energy (LCoE) is proposed as a measure of the profitability of the wind power project. The LCoE is one of the most commonly used indicators employed by both industry and regulators to assess the economic performance of wind projects. For a given potential solution, $x$, The LCoE of the project for the estimated life span, $L$, can be calculated as follows: 
Table I. - Costs model of wind turbine components depending on rated power, rotor radius and hub height [8].

\begin{tabular}{|l|l|}
\hline \multicolumn{1}{|c|}{ Component } & \multicolumn{1}{c|}{ Cost $[\$]$} \\
\hline Blades & $\left(1.6745 \cdot R^{3}-3980.2\right) \cdot B C E+11.435 \cdot R^{2.5025} \cdot G D P E$ \\
\hline Hub & $0.5886 \cdot R^{2.9158}+206.1 \cdot R+21241.8$ \\
\hline Pitch control system & $3.0304 \cdot R^{2.6578}$ \\
\hline Nacelle & $0.7397 \cdot R^{2.887}$ \\
\hline Low-speed shaft & $0.04873 \cdot R^{3.5}-0.06047 \cdot R^{2.5}$ \\
\hline Main bearings & $16.45 \cdot P_{n}{ }^{1.249}$ \\
\hline Gearbox & $1.989 \cdot P_{n}-0.1141$ \\
\hline Brake system & $65 \cdot P_{n}$ \\
\hline Generator & $79 \cdot P_{n}$ \\
\hline Converter & $0.529 \cdot R^{2.964}$ \\
\hline Yaw system & $36.739 \cdot R^{1.953}$ \\
\hline Main frame & $40 \cdot P_{n}$ \\
\hline Electric connections & $12 \cdot P_{n}$ \\
\hline Hydraulic and cooling system & $11.537 \cdot P_{n}+3849.7$ \\
\hline Nacelle cover & 35000 \\
\hline Control and data acquisition system & $1.5 \cdot\left(0.3973 \cdot \pi R^{2} \cdot H-1414\right)$ \\
\hline Tower & $303.24 \cdot\left(H \cdot \pi R^{2}\right)^{0.4037}$ \\
\hline & $1.581 \cdot 10^{-5} \cdot P_{n}{ }^{3}-0.0375 \cdot P_{n}{ }^{2}+54.7 \cdot P_{n}$ \\
\hline Foundations & $2.17 \cdot 10-6 \cdot P_{n}{ }^{3}-0.0145 \cdot P_{n}{ }^{2}+69.54 \cdot P_{n}$ \\
\hline Transport & $3.49 \cdot 10-6 \cdot P_{n}{ }^{3}-0.0221 \cdot P_{n}{ }^{2}+109.7 \cdot P_{n}$ \\
\hline Civil works & $9.94 \cdot 10-4 \cdot P_{n}{ }^{2}+20.31 \cdot P_{n}$ \\
\hline Electricity infrastructure & \\
\hline Engineering and permits & Balance of plant \\
\hline
\end{tabular}

$$
L C o E(x)=\frac{I_{W T}(x)+\sum_{k=1}^{L} \frac{C(x)_{\text {O\&M } k}}{(1+r)^{k}}}{\sum_{k=1}^{L} \frac{A E P(x)}{(1+r)^{k}}}
$$

where $I_{W T}(x)$ is the investment or cost of wind turbines; $C(x)_{\mathrm{O} \& \mathrm{M}}$ is the annual cost of operation and maintenance; $A E P(x)$ is the annual energy produced; and $r$ is the discount rate.

In order to assess the initial investment on wind turbines, $I_{W T}(x)$, the costs model implemented by NREL has been considered [8], which takes into account the influence of rotor diameter, $R$, nominal power, $P_{n}$, and tower height, $H$, on the individual cost of each of the components of the wind turbine. This cost model is summarized in Table I. It is also worth mentioning that this model dates back to 2006. Therefore, costs of some components have been updated by means of two escalation coefficients: the blade material cost escalator (defined in [8] as BCE) and the labour cost escalator (defined in [8] as GDPE).

The second objective is the maximization of the capacity factor, which is calculated as follows:

$$
C F(x)=\frac{A E P(x)}{T \cdot P_{n}(x)}
$$

\section{Test cases}

This section aims at showing the ability of the proposed methodology to optimise the main design variables of a wind turbine seeking for minimizing the $\mathrm{LCoE}$ at the same time as maximizing the capacity factor.

This test case considers a wind farm composed by several wind turbines (assuming a $k_{\text {losses }}$ factor of 0.9 , which considers losses due to wakes, electrical losses, among other) placed at a location where the wind conditions are defined by a Scale Factor of $C=7.5 \mathrm{~m} / \mathrm{s}$ (at $80 \mathrm{~m}$ height) and a of Shape Factor $K=2$. The roughness length of the terrain at the location under study is assumed to be $0.005 \mathrm{~m}$. A power coefficient of 0.4229 is considered to define the power curve of the wind turbines and an air density of $1.225 \mathrm{~kg} / \mathrm{m}^{3}$. The cut-in and cut-out speed of the wind turbine of $3 \mathrm{~m} / \mathrm{s}$ and $25 \mathrm{~m} / \mathrm{s}$, respectively. The life span of the project has been assumed to be 20 years, the interest rate is $8 \%$ and the operation and maintenance costs are $7 \$ / \mathrm{MWh}$. The optimization variables range is defined by the following lower and upper limits: $0.5-4.0$ MW for the wind turbine rated power, $160-400 \mathrm{~W} / \mathrm{m} 2$ for the specific power and $0.6-1.5$ for the ratio between hub height and rotor diameter.

Figure 1 shows the Pareto Frontier obtained by the proposed multi-objective genetic algorithm. As it can be observed, the solution with lowest LCoE (59.72 \$/MWh)

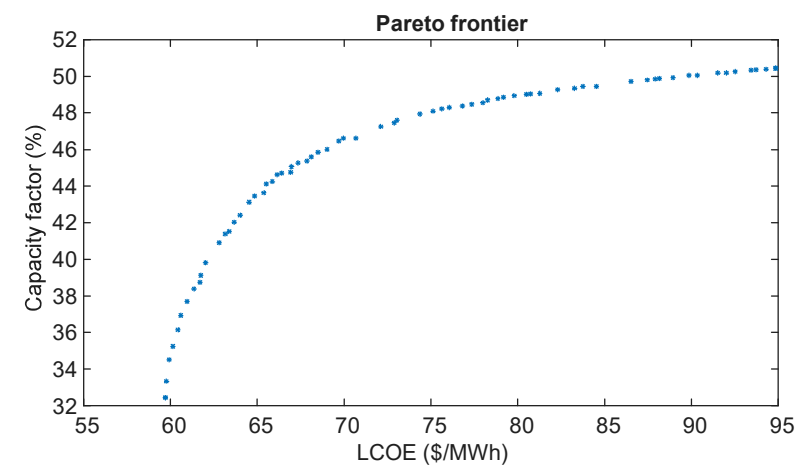

Figure 1. Pareto Frontier obtained for the proposed test case. 

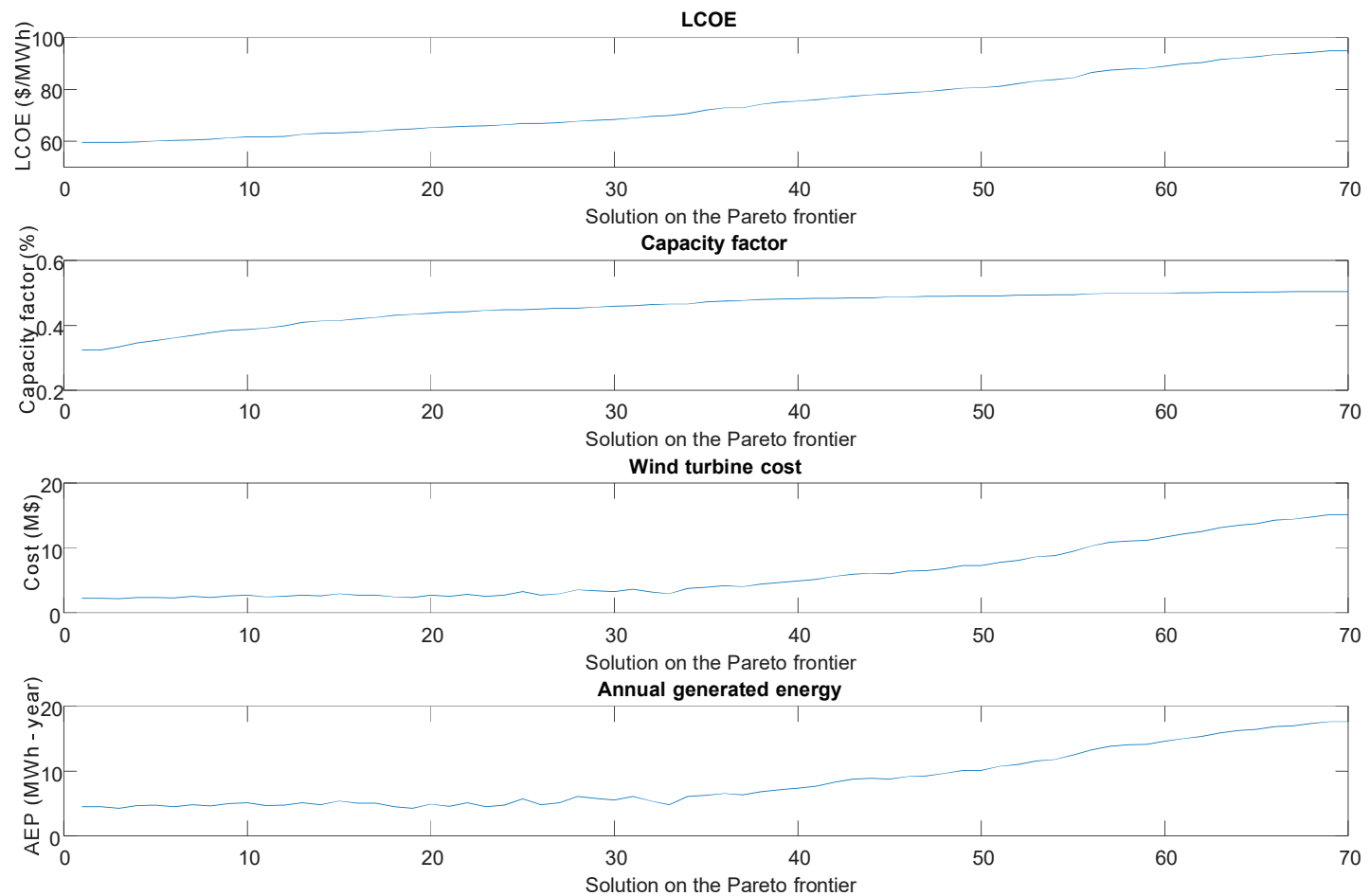

Figure 2. Evolution of main techno-economic outputs for the solutions obtained on Pareto Frontier.

provides also the lowest capacity factor $32.43 \%$, this solution would be the obtained by the classical approach that seeks just for minimizing the LCoE. However, the proposed methodology enable to choose another different design options with higher LCoE but also with higher capacity factor along the Pareto Frontier. For example, by increasing the LCoE by around $10 \%$ (taking a solution with a LCOE of $65.85 \$ / \mathrm{MWh}$ ) a capacity factor of 44.24 $\%$ can be found, i.e., with a capacity factor around a $20 \%$ higher (with the associated benefits in terms of better plant integration). Figure 2 shows the evolution of main technoeconomic outputs for the optimal Pareto solutions obtained by the proposed multi-objective approach.

\section{Conclusion}

This paper presents a novel approach which aims at optimizing the design of wind turbines, not only seeking for minimizing the levelised cost of energy but also by maximizing the capacity factor, which would reduce, to some extent, the intermittency of wind generation.

The proposed new approach can be of interest for current wind industry, as cost reductions is leading wind energy technology to achieve similar generation costs than conventional sources, at the same time as manufacturers are increasingly focusing their effort in offering more tailored designs of wind turbines.

Nevertheless, it is worth to mention that the work presented in this paper is a theoretical exercise and the real applicability of the proposed approach will be subject to accuracy of the cost models as well as the ability of wind turbine manufacturers to offer tailored designs of the main design variables of the wind turbine. In particular, rotor diameter and hub height are variables of design that are achieving a higher degree of customization, whilst rated power is, in practical terms, a less flexible variable, as it implies the customization of several expensive components such as electric generator, gearbox and power converter.

\section{Acknowledgement}

This work was supported in part by the Spanish Ministry of Economy, Industry and Competitiveness under grant ENE2016-77650-R, and by 3DMicroGrid (PCIN-2015043) project.

\section{References}

[1] "Hyller: developing a cost-effective, flexible blade length concept." [Online]. Available: https://www.lmwindpower.com/en/products-andservices/innovate-for-excellence/our-projects/hyller.

[2] S. H. Jangamshetti and V. Guruprasada Rau, "Normalized power curves as a tool for identification of optimum wind turbine generator parameters," IEEE Trans. Energy Convers., vol. 16, pp. 283-288, 2001.

[3] Y. Ditkovich, A. Kuperman, A. Yahalom, and M. Byalsky, "Site-dependent wind turbine performance index," Int. J. Renew. Energy Res., vol. 3, no. 3, pp. 592594, 2013.

[4] Y. Ditkovich, A. Kuperman, A. Yahalom, and M. Byalsky, "Alternative Approach to Wind Turbine Performance Index Assessment," J. Energy Eng., vol. 140, no. 4, p. 6014001, 2014.

[5] F. A. L. Jowder, "Wind power analysis and site matching of wind turbine generators in Kingdom of Bahrain," Appl. Energy, vol. 86, pp. 538-545, 2009.

[6] M. H. Albadi and E. F. El-Saadany, "Optimum turbine-site matching," Energy, vol. 35, no. 9, pp. 35933602, 2010.

[7] S. yuan $\mathrm{Hu}$ and J. ho Cheng, "Performance evaluation of pairing between sites and wind turbines," Renew. Energy, vol. 32, no. 11, pp. 1934-1947, 2007.

[8] L. Fingersh and M. Hand, "Wind turbine design cost and scaling model," Natl. Renew. Energy \{...\}, 2006. 